\title{
The Present State of Chemical State Analysis in EPMA and WD-SXES
}

\author{
Norihisa Mori, Takanori Murano and Hideyuki Takahashi
}

JEOL Ltd., 1-2 Musashino, 3 Akishima, Tokyo 196-8558 Japan

Chemical state analysis in EPMA examines changes in the characteristic X-ray spectrum reflecting the electronic structure of a specific element in a material. Waveforms of characteristic X-rays reflecting low energy electronic structures often change according to the chemical bonding state. Chemical state analysis in EPMA focuses on these changes in the waveform. This analysis determines the composition of the chemical state identifies the chemical state by comparing the waveforms of an unknown material and a reference material.

Changes reflecting the chemical state of the sample are observed by capturing characteristic X-rays in a high resolution spectrometer system. Since EPMA has sufficiently high wavelength resolution, it can conduct analysis of the chemical state using $\mathrm{K}$ line of a light element, L line of a transition metal, and $\mathrm{M}$ line of rare earth (Figure 1).

However, there are a few problems in the analysis of state with EPMA. Since EPMA is a kind of monochromator, it $\mathrm{i}$ s necessary to scan in order to obtain a spectrum. Another po int is that the wavelength resolution (energy resolution) of X-rays in EPMA is inferior to that in either AES or XPS. The latter methods are most commonly used chemical state analysis.

A wavelength dispersive soft X -ray e mission spe ctrometer (WD-SXES ) which we have $\mathrm{r}$ ecently developed $\mathrm{c}$ an solve th ese tw o problems [ $1,2,3]$. The energy resolution of th is WD-S XES is nominally $0.3 \mathrm{eV}$, which is more than an order of magnitude better than that of the conventional WDS with layered dispersion elements used for light elements in EPMA. One other useful characteristic of this WD-SXES is parallel detection of the X-rays, which makes its operation just like the conventional energy dispersive spectrometer for EPMA.

WD-SXES can be installed to EPMAs. Therefore, Li can be added to the analysis range. It confirms the high potential WD-SXES for the characterization of material based on chemical state due to th is high energy resolution (Figure 2).

Although WD-SXES and EPMA can be used for chemical state analysis, actual spectra of defined chemical state a re not known widely in $\mathrm{m}$ any $\mathrm{c}$ ases. In this pres entation we shows spectra of well defined chemical state for about ten elements, which can be used for the chemical state analysis in WD-SXES and EPMA.

\section{References:}

[1] M.Terauchi, M.Koike, K.Fukushima and J.Kimura: 16th Intl. Conf. Microscopy, 892 (2006).

[2] M.Terauchi, H.Takahashi, H.Nobuo, T.Murano, M.Koike, T.Kawachi, T.Imazono, M.Koeda, T.Nagano, H.Sasai, Y.Oue, Z.Yonezawa, S.Kuramoto, J. Electron Microscopy, 61, 1 (2012).

[3] T.Imazono, M.Koike, T.Kawachi, N.Hasegawa, M.Koeda, T.Nagano, H.Sasai, Y.Oue, Z.Yonezawa, S.Kuramoto, M.Terauchi, H.Takahashi, N.Handa, T.Murano and K.Sano, Appl. Opt, 51, 2351 (2012). 

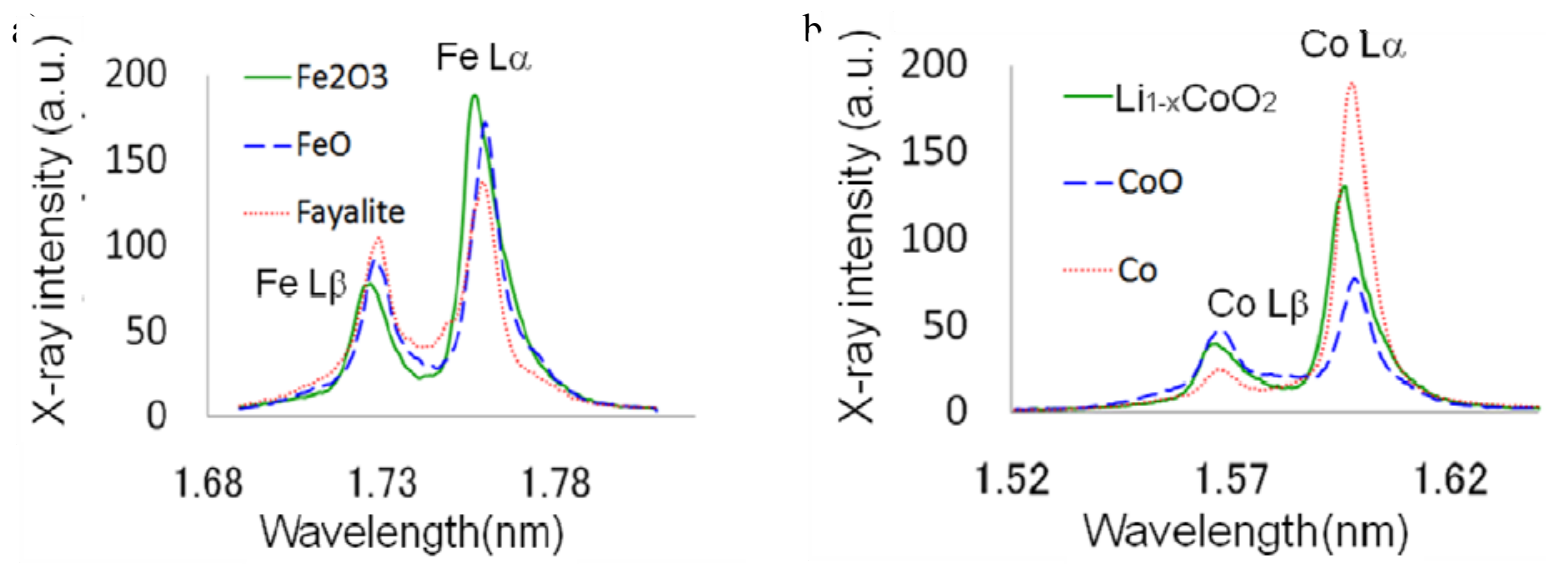

Figure 1. The chemical state spectrum by EPMA. The example of analysis of the various compounds by Fe L line ( a ) and Co L line ( $b$ ).

a)

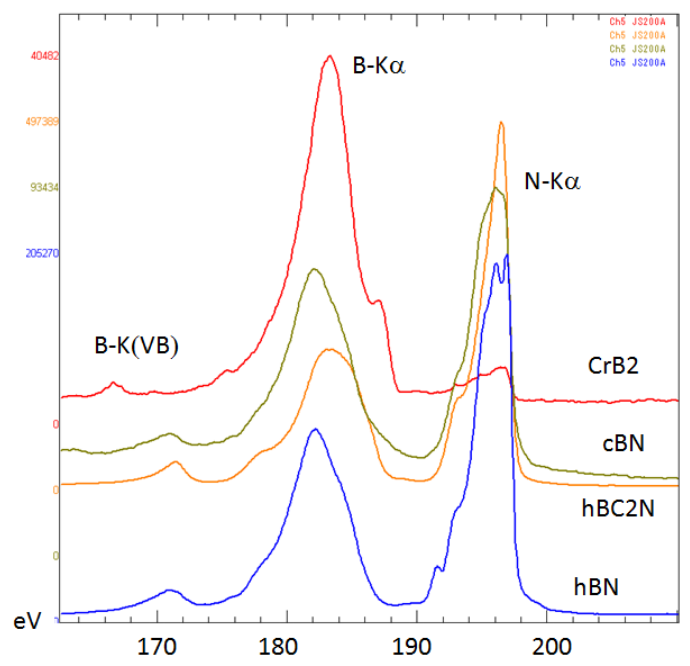

b)

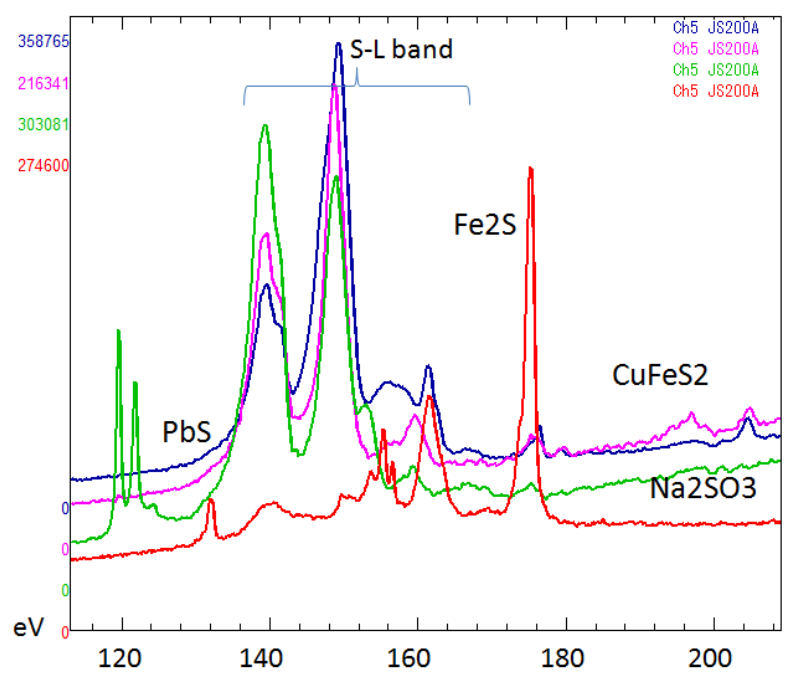

Figure 2. Th e ch emical state spectrum by WD-SXES. Th e ex ample of an alysis of the $\mathrm{v}$ arious compounds by B K line, N K line ( a ) and S L line ( $b$ ). 